\title{
Vulnerability of east Siberia's frozen carbon stores to future warming
}

\author{
D. V. Khvorostyanov, ${ }^{1,2}$ P. Ciais, ${ }^{1}$ G. Krinner, ${ }^{3}$ and S. A. Zimov ${ }^{4}$ \\ Received 14 February 2008; revised 6 April 2008; accepted 10 April 2008; published 20 May 2008.
}

[1] East Siberia's permafrost contains about $500 \mathrm{GtC}$ of frozen highly labile carbon deposits, a so-called Yedoma. Using a permafrost carbon cycle model we analyzed mobilization of this huge carbon stock in a future warming. Conditions necessary to trigger the irreversible Yedoma thawing maintained by deep respiration and methanogenesis are studied. Once started, this process

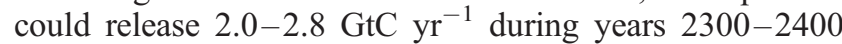
transforming $75 \%$ of initial carbon stock into $\mathrm{CO}_{2}$ and methane. The time when the fast deep-soil decomposition starts is inversely proportional to the warming rate, while the corresponding (critical) temperature anomaly slightly increases at larger warming rates. This second-order effect is due to the deep-soil heat storage caused by external warming, which leads to more homogeneous soil heating when the warming is slower, and so a smaller external warming is needed to thaw the permafrost. The effect of specific microbial heat that accompanies oxic decomposition is of comparable importance to that of the warming rate on the critical temperature anomaly, while it is of minor importance on the time when deep decomposition starts. Citation: Khvorostyanov, D. V., P. Ciais, G. Krinner, and S. A. Zimov (2008), Vulnerability of east Siberia's frozen carbon stores to future warming, Geophys. Res. Lett., 35, L10703, doi:10.1029/ 2008GL033639.

\section{Introduction}

[2] Northern high latitudes are known to be sensitive areas of the global climate system. The warming rates in the Arctic were found to be almost two times the global average rate in the past 100 years. Temperatures at the top of the permafrost layer have increased by up to $3^{\circ} \mathrm{C}$ since the 1980s [Intergovernmental Panel on Climate Change (IPCC), 2007]. Apart from land biophysical feedbacks at high latitudes occurring via trends in seasonal albedo and vegetation cover [Chapin et al., 2005; Zhang and Walsh, 2007], changes in hydrology [National Research Council, 2003] and in thawing depth [Frauenfeld et al., 2004, 2007; Zhang et al., 2005], a potentially important and yet poorly quantified positive feedback of high latitudes ecosystems on future climate change is the loss of $\mathrm{CO}_{2}$ and $\mathrm{CH}_{4}$ from frozen soil carbon. Permafrost currently covers about 23 millions $\mathrm{km}^{2}$ of northern continents and contains large

\footnotetext{
${ }^{1}$ Laboratoire des Sciences du Climat et l'Environnement, IPSL/ CEA-CNRS-UVSQ, Saclay, France.

${ }^{2}$ A. M. Obukhov Institute of Atmospheric Physics RAS, Moscow, Russia.

${ }^{3}$ Laboratoire de Glaciologie et Géophysique de l'Environnement, CNRS-UJF-OSUG, Saint Martin d'Hères, France.

${ }^{4}$ Northeast Science Station, Cherskii, Russia.
}

stock of organic carbon that possibly exceeds $950 \mathrm{Gt}$ [Zimov et al., 2006]. The latter estimate implies that frozen carbon constitutes about $63 \%$ of the global soil carbon stock. Eastern Siberia alone contains about $500 \mathrm{Gt}$ of frozen carbon as loess deposits forming the Yedoma (or the Ice Complex) [Zimov et al., 2006]. This large carbon pool is likely to be labile because it has not undergone much alteration by soil microorganisms since its formation, which took place from the Last Glacial Maximum back to 40,000 years ago, when eastern Siberia was covered by cold steppes [Zimov et al., 2006].

[3] The goal of this study is to assess the vulnerability of soil carbon in the Yedoma to future warming. To meet that goal, we use a model of heat transfer and soil organic matter decomposition in frozen soils described in [Khvorostyanov et al., 2008a, 2008b] (hereafter K08) and Poutou et al. [2004]. One of the particularities of this model is taking into account the heat production by soil microbial activity and for decomposition of soil organic matter into either $\mathrm{CO}_{2}$ or $\mathrm{CH}_{4}$, depending on oxygen availability in the soil depth. The study of K08 has shown that, once active layer deepening in response to atmospheric warming is enough to trigger deep-soil respiration, and soil microorganisms are activated to produce enough heat, the mobilization of soil carbon can be very strong and self-sustainable. The carbon mobilization is irreversible and occurs within 50 to 100 years, which outgases huge amounts of $\mathrm{CO}_{2}$ to the atmosphere (at an average rate of up to $2.1 \mathrm{kgC} \mathrm{m}^{-2} \mathrm{yr}^{-1}$ ). Even when soil oxygen becomes later on too scarce and limits decomposition, $\mathrm{CH}_{4}$ production takes over and continues to generate enough heat to sustain the thawing of permafrost carbon for another few decades.

[4] We define here the vulnerability of the Yedoma carbon as the tipping point of the future regional warming $\left(T_{\text {crit }}\right)$ above which soil carbon starts irreversible mobilization due to permafrost thawing. We address the question if the value of this tipping point depends only on the magnitude of the atmospheric temperature rise, or also on the warming rate, which governs the additional amount of heat available for triggering the irreversible thawing at a given time horizon. The value of the tipping point depends on the heat delivered by microbial decomposition (in the presence of oxygen). This model parameter has a large uncertainty, since it depends on the quality of the organic substrate.

[5] In the following, we first describe the frozen soil organic carbon decomposition model set up and parameters, as well as the future warming scenarios that were constructed to map the vulnerability (in section 2). In section 3, the sensitivity of $T_{\text {crit }}$ to the model parameters and to the future warming trajectory is investigated, and maps of $T_{\text {crit }}$ 

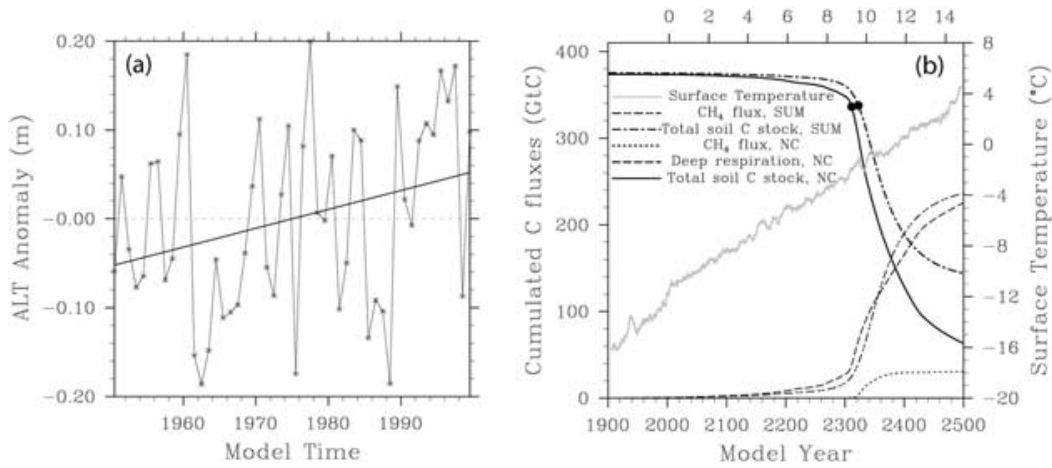

Figure 1. (a) Simulated acitve layer thickness (ALT) variations during the second half of the 20th century computed from Yedoma region averaged soil temperature. The straight line shows linear trend. (b) Carbon balance at normal conditions (NC) and saturated upper soil meter (SUM). The y-axis gives total carbon stock for NC and SUM cases, as well as cumulated carbon fluxes. Circles show the time and carbon density when 10\% of initial carbon are mobilized. Upper axis shows the surface temperature anomaly added to the observed temperature field since 2002. The grey curve shows 10 -year running mean surface temperature.

are produced and discussed. Section 4 concludes about the article's results.

\section{Model and Experimental Design}

[6] The model used is that described in K08 and Poutou et al. [2004]. It computes vertical profiles of soil temperature, soil carbon density, moisture of the upper soil meter, concentrations of soil $\mathrm{O}_{2}$ and $\mathrm{CH}_{4}$. It takes into account in particular microbial heat release that accompanies decomposition of soil organic matter. The latter parameter is found in K08a to be quite sensitive for the model behavior.

[7] In order to study the soil response to the climate warming pattern, the model forcing procedure was the following. After 900-year spinup the model reached its equilibrium with the atmospheric temperature of early industrial times, year 1901 from observation data. The latter was computed from the Climate Research Unit (CRU, $\mathrm{http}: /$ www.cru.uea.ac.uk/) dataset for the Yedoma region in the north-eastern Siberia [Zimov et al., 2006; Walter et al., 2006]. Yedoma is characterized by very high carbon density $\left(21 \mathrm{kgC} \mathrm{m}^{-3}\right)$, high carbon deposit depth (average depth of $25 \mathrm{~m}$ ), and high lability of the soil organic matter [Zimov et al., 2006]. For our simulations, we considered the area between $150 \mathrm{E}-168 \mathrm{E}$ and $63 \mathrm{~S}-70 \mathrm{~S}$ shown in Figure $3 \mathrm{a}$. Observed climate conditions of the 20th century were then applied according to the same CRU data until 2002. Then the soil surface temperature was increased linearly at a rate $\delta T_{100}$ ranging from 3 to $8^{\circ} \mathrm{C}(100 \mathrm{yr})^{-1}$. We also compared the case where the upper-meter soil moisture is computed from the model's hydrology scheme to that where it is always saturated, which occurs when the runoff is insufficient to remove the meltwater.

\section{Results}

[8] One of the main characteristics that determines carbon cycling in frozen soils is active layer thickness (ALT). It has been reported to have increased by about $20 \mathrm{~cm}$ from 1956 to 1990 , on the basis of soil temperature measurements at 31 permafrost stations in Russia [Frauenfeld et al., 2004; IPCC, 2007]. Among the main parameters that influence
ALT variations are summer air temperatures, maximum snow depth, and thawing index [Frauenfeld et al., 2004, 2007]. Our model simulation shows statistically significant (at the level of 95\%) ALT increase during the last half of the 20th century, based on the Yedoma region average soil temperatures (Figure 1a). The mean ALT increase over this period is about $11 \mathrm{~cm}$, i.e., about two times slower than from the in situ measurements for the Russian permafrost area. Our study region has a colder climate: most of its territory is situated in the Sakha republic known for being the coldest region of the northern hemisphere (mean annual air temperatures of $-10--20^{\circ} \mathrm{C}$ ). Its ALT is probably less sensitive to warming than in more southern areas. Moreover numerical modeling results, as well as thawing index estimates, have been already found to underestimate the ALT trend in comparison to the "ground truth" of site measurements [Zhang et al., 2005]. Thawing index computed from gridded monthly temperature datasets for the Russian permafrost regions have not manifested any statistically significant trends at all for the period of interest [Frauenfeld et al., 2007]. In our model, simulated ALT shows statistically significant positive correlation with maximum and summer air temperatures and soil moisture (not shown).

[9] Figure $1 \mathrm{~b}$ shows the simulated carbon balance of the Yedoma region corresponding to $\delta T_{100}=3^{\circ} \mathrm{C}(100 \mathrm{yr})^{-1}$ for the normal (nonsaturated) soil and that with saturated upper meter. About $75 \%$ of the $380 \mathrm{GtC}$ present by year 1900 after the spinup are quickly mobilized in 100 years between 2300 and 2400 in the case of normal soil. The average carbon

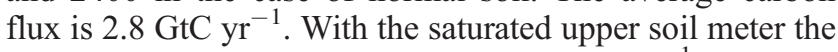

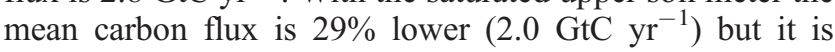
emitted as methane with accumulated value attaining $180 \mathrm{GtC}$ by 2400 (Figure 1b).

[10] Temperature anomaly is $9.2^{\circ} \mathrm{C}$ for nonsaturated and $9.6^{\circ} \mathrm{C}$ for saturated soil, when $10 \%$ of initial carbon stock (C) are mobilized, and the intense carbon mobilization starts. At normal conditions, the primary mechanism for carbon mobilization is the deep soil respiration explaining $64 \%$ of the total carbon release. Methane flux accounts for $12 \%$ of the total carbon mobilization. Note that the total soil carbon stock includes that related to litter fall and respira- 

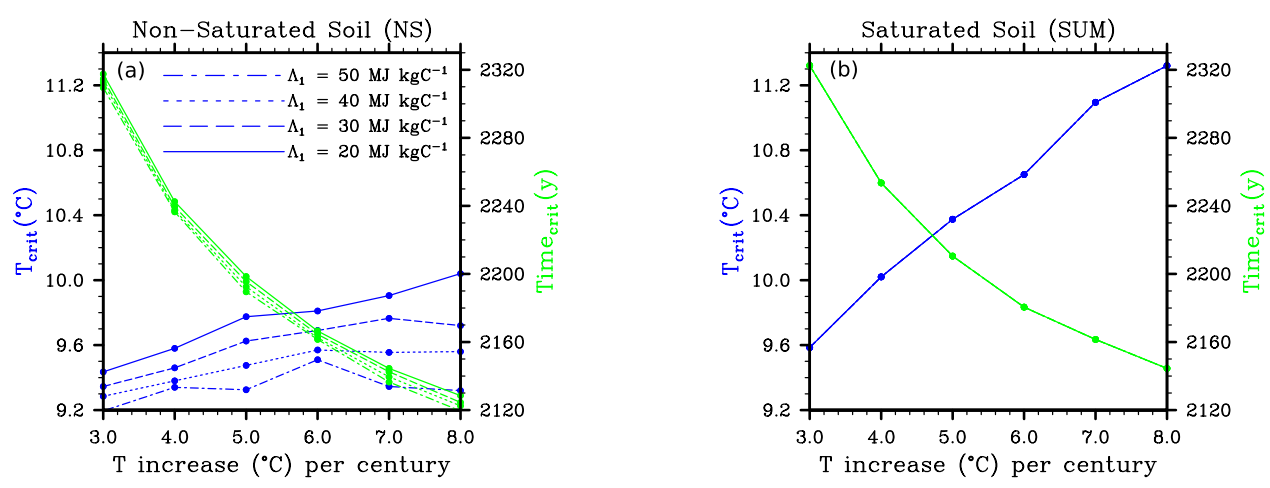

Figure 2. (a) Nonsaturated soil. (b) Saturated soil. Critical surface temperature anomaly (left axes) and model year (right axes) at which $10 \%$ of the initial carbon stock are mobilized, and irreversible deep carbon mobilization starts, as a function of temperature increase per century at various values of specific microbial heat $\Lambda_{1}$.

tion being about $100 \mathrm{kgC}$ over the $1500 \mathrm{yr}$ of simulation. When the upper soil meter is saturated, the only mechanism of carbon mobilization is methanogenesis. At the rate of temperature increase of $3^{\circ} \mathrm{C}(100 \mathrm{yr})^{-1}, 190 \mathrm{GtC}$ are emitted to the atmosphere in the form of methane by 2400 , which is the half of the initial stock.

[11] Figure 2 shows the sensitivity of the mobilized carbon to the temperature increase rate and to one of the most sensitive model parameters, specific microbial heat. For the cases considered, mobilization of $10 \%$ carbon corresponds to triggering of the deep soil respiration and consequent fast mobilization of the large carbon stocks shown in Figure $1 \mathrm{~b}$. The temperature anomaly $T_{\text {crit }}$ necessary to trigger the deep decomposition increases with $\delta T_{100}$ (Figure 2), that is, for a faster warming a slightly greater warming magnitude is required. The temperature anomaly decreases with increasing oxic decomposition specific heat (Figure 2a). The order of magnitude is the same with respect to both parameters. At the reference value of the specific heat $(40 \mathrm{MJ} / \mathrm{kgC}) T_{\text {crit }}$ varies between 9.3 and $9.6^{\circ} \mathrm{C}$ when $\delta T_{100}$ varies from 3 to $8^{\circ} \mathrm{C}(100 \mathrm{yr})^{-1}$, and the soil is nonsaturated. For the saturated soil $T_{c r i t}$ is greater, as well as its sensitivity to $\delta T_{100}: 9.6$ to $11.4^{\circ} \mathrm{C}$. When $\delta T_{100}=3^{\circ} \mathrm{C}$ $(100 \mathrm{yr})^{-1}, T_{\text {crit }}$ decreases from 9.5 to $9.2^{\circ} \mathrm{C}$ at the specific heat ranging from 20 to $50 \mathrm{MJ} / \mathrm{kgC}$. The dependence is slightly stronger at larger $\delta T_{100}$ values: from 10 down to $9.4^{\circ} \mathrm{C}$ at $\delta T_{100}=8^{\circ} \mathrm{C}(100 \mathrm{yr})^{-1}$. When the soil is saturated, there is no oxic decomposition (no dependence on the specific heat in Figure 2b), since concentration of oxygen dissolved in soil pores is insufficient to sustain it (see K08). The whole range of $T_{\text {crit }}$ changes is from 9.2 to $10.0^{\circ} \mathrm{C}$ for nonsaturated and from 9.6 to $11.4^{\circ} \mathrm{C}$ for saturated soil, respectively, at the chosen range of parameter variations.

[12] The activation time is inversely proportional to $\delta T_{100}$ with the dependence on the specific heat being of the second order of magnitude. The time changes between 2120 and 2318 (118 and 316 years of warming since 2002) for nonsaturated and between 2144 and 2322 (142 and 320 years of warming) for saturated soil.

[13] Figure $3 \mathrm{~b}$ shows the surface air temperature anomaly during the 20th century calculated as the difference in the linear trend between 1901 and 2002 after filtering out seasonal cycle with one-year running means. The 20th century anomaly has a pronounced west-east structure, and its spatial variation is about $1.4^{\circ} \mathrm{C}$. Figures $3 \mathrm{c}-3 \mathrm{f}$ show spatial distributions of the temperature anomaly for the Yedoma region for four cases: saturated and unsaturated soil at $\delta T_{100}=3$ and $5^{\circ} \mathrm{C}(100 \mathrm{yr})^{-1}$. In all the four cases minimum anomaly is found in the coastal area in the southeastern part of the region (down to $6.9^{\circ} \mathrm{C}$ in Figure 3e). Maximum anomalies occur in the northeast and southwest of the region (up to $11.3^{\circ} \mathrm{C}$ in Figure $3 \mathrm{f}$ ). In most of the area a slightly smaller anomaly is required to activate deep-soil decomposition at $\delta T_{100}=3^{\circ} \mathrm{C}(100 \mathrm{yr})^{-1}$, although minimum $T_{\text {crit }}$ value is found at $\delta T_{100}=5^{\circ} \mathrm{C}$ $(100 \mathrm{yr})^{-1}$ (Figure $\left.3 \mathrm{e}\right)$. When the upper soil is saturated (Figure 3d, 3f), larger anomalies are found in the whole region at both considered warming rates. Maximum $T_{\text {crit }}$ values are required at the higher warming rate $\delta T_{100}=5^{\circ} \mathrm{C}$ $(100 \mathrm{yr})^{-1}$. The total spatial variation of $T_{\text {crit }}$, including both saturated and nonsaturated conditions, is 2.7 and $3.0^{\circ} \mathrm{C}$ at $\delta T_{100}=3$ and $5^{\circ} \mathrm{C}(100 \mathrm{yr})^{-1}$, respectively. This is about two times larger than that of the 20th century anomaly shown in Figure 3b.

\section{Conclusion}

[14] The influence of warming rate and specific microbial decomposition heat on the time and temperature anomaly corresponding to triggering of fast irreversible deep-soil organic matter decomposition was studied. Dependence of time is a linear process, the time when deep decomposition starts is inversely proportional to the warming rate. The increase of $T_{\text {crit }}$ with the warming rate is a second order process, reflecting the fact that the soil is heated more homogeneously at a slower temperature increase, more heat is accumulated in the soil, and a less amount of additional heat from the surface is needed to trigger the deep permafrost thawing and associated decomposition. Once started,

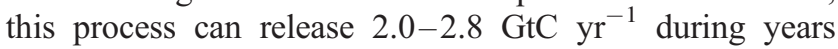
$2300-2400$ transforming $75 \%$ of the initial carbon stock into $\mathrm{CO}_{2}$ and methane.

[15] Specific microbial heat of oxic decomposition was found in K08 to be one of the most sensitive model parameters, and its value is unknown for Yedoma. We showed in this work that this parameter has little effect on the time of deep decomposition activation, while it is of comparable importance to that of the warming rate for the $T_{\text {crit }}$ anomaly. The greater the specific heat the more heat is produced in the soil, the faster the soil is warmed up in 


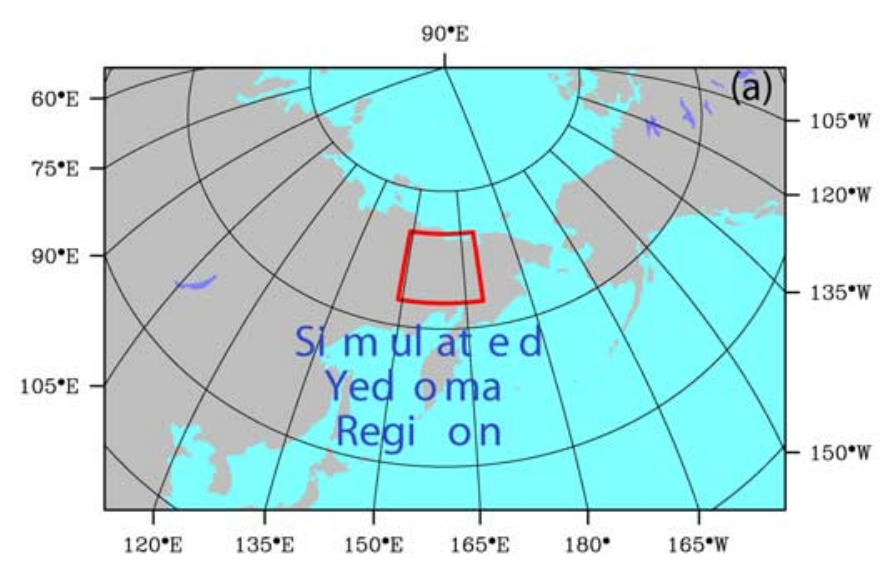

Non-Saturated Soil
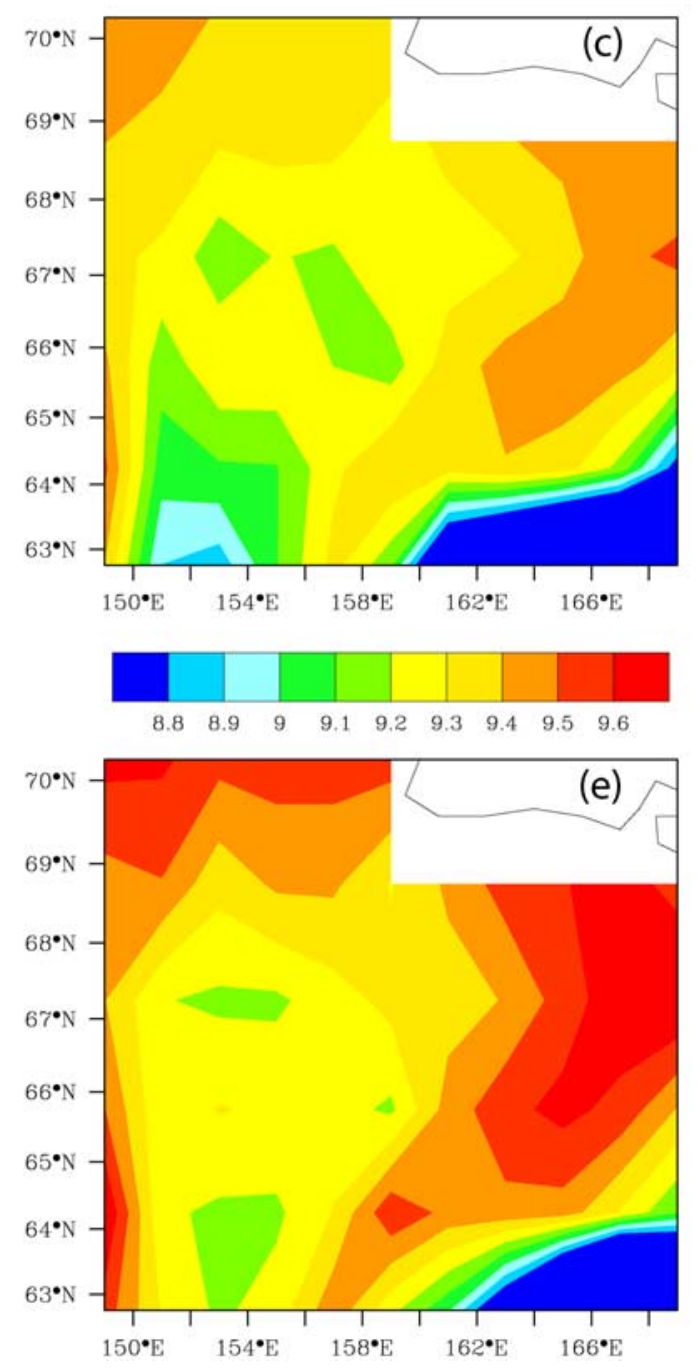

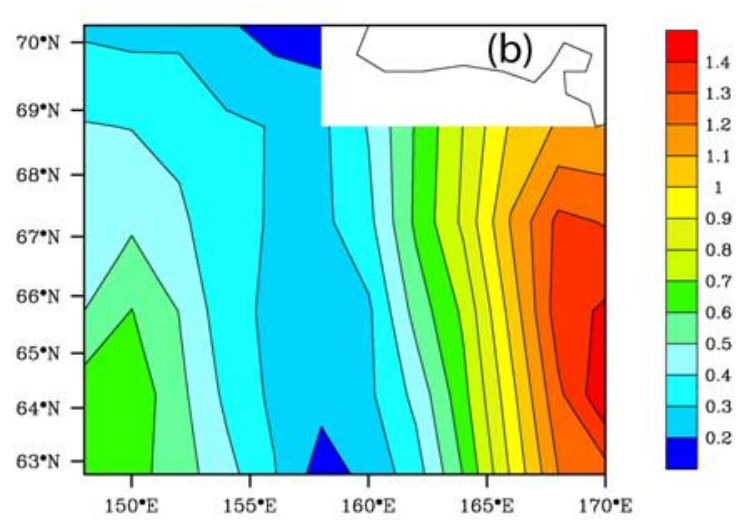

Saturated Soil
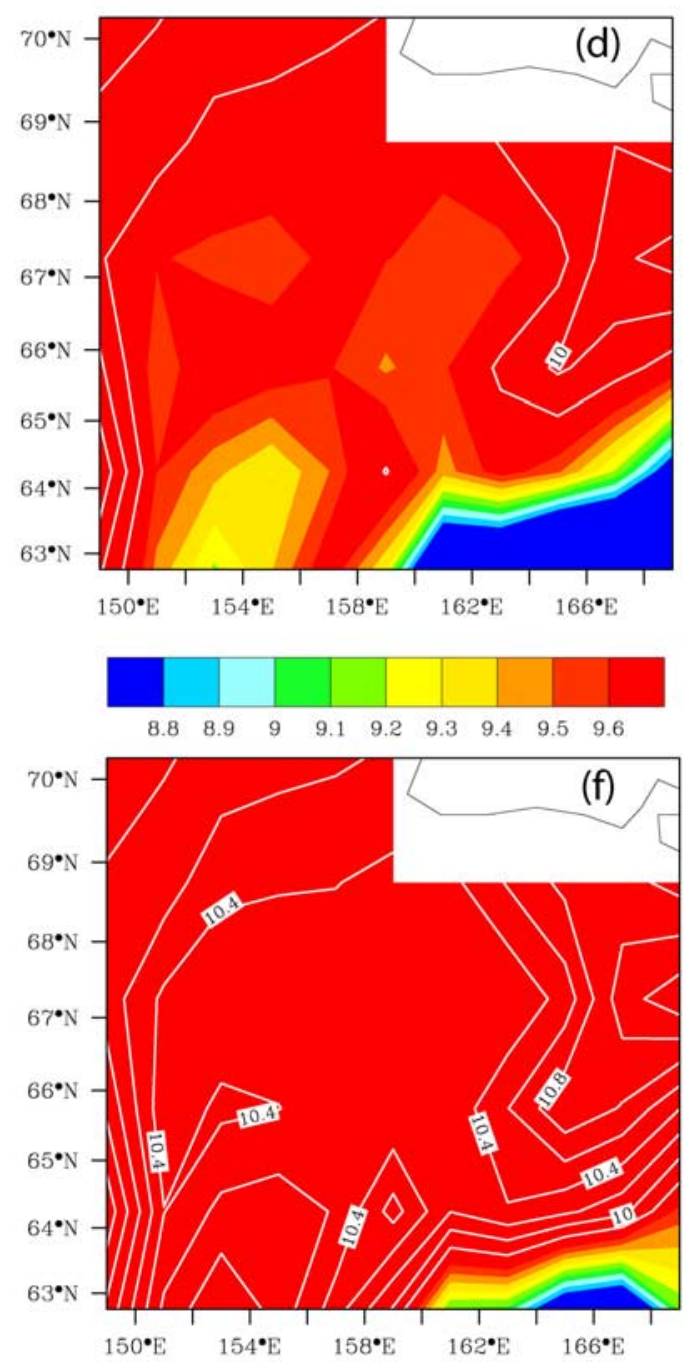

Figure 3. (a) Simulated Yedoma region, (b) temperature anomaly for the 20th century and for the future (c, d) at $\mathrm{T}_{100}=3^{\circ} \mathrm{C}(\mathrm{e}, \mathrm{f})$ at $\mathrm{T}_{100}=5^{\circ} \mathrm{C}$ for normal conditions (c, e) and saturated soil upper meter $(\mathrm{d}$, f). White contours start from $9.8^{\circ} \mathrm{C}$ with the interval $0.2^{\circ} \mathrm{C}$.

depth and responds to the surface warming. So the deep decomposition occurs earlier and corresponds to a smaller surface temperature anomaly.

[16] The spatial variation of $T_{c r i t}$ in the Yedoma region considered is about two times greater than the spatial variation of the current warming over the 20th century indicating that the response of Yedoma carbon will be quite heterogeneous. Anomalies are larger when the upper soil is saturated at both considered warming rates. When Yedoma thaws, melting of ice wedges can lead to formation of 
thermokarst ponds and then lakes. According to years of observations (S.A. Zimov, unpublished data, 2007), thermokarst water is quickly runoff during summer, forming well-aerated hills, at about $80-85 \%$ of the thawed Yedoma area. The soils between the hills still emit methane at a few meters depth due to the lack of oxygen. The average soil moisture of these thawed Yedoma regions is $30-50 \%$ (see also K08). This corresponds to our NC experiment. Flooded thermokarst regions are preserved for decades at the remaining $15-20 \%$ of the thawed Yedoma area (the SUM experiment).

[17] The model used here does not take into account the cycles of nitrogen and phosphorous, whose availability can influence soil respiration. A simple bucket scheme used for hydrology also neglects changes in the ground water level, which can affect the balance between production of $\mathrm{CO}_{2}$ or $\mathrm{CH}_{4}$ in the soil. Further studies are needed that will include a coupled hydrological model capable of simulating flooded and dry areas being sources of methane and $\mathrm{CO}_{2}$.

[18] Acknowledgments. The authors are grateful to Pierre Friedlingstein and Nicolas Viovy for helpful discussions and to anonymous reviewers for useful revision suggestions. D. V. Khvorostyanov also thanks Masa Kageyama and Didier Paillard for partial funding of his work (Prix Louis D. de l'Académie des Sciences, 2004).

\section{References}

Chapin, F. S., III, et al. (2005), Role of land-surface changes in Arctic summer warming, Science, 310, 657-660.

Frauenfeld, O. W., T. Zhang, R. G. Barry, and D. Gilichinsky (2004), Interdecadal changes in seasonal freeze and thaw depths in Russia, J. Geophys. Res., 109, D05101, doi:10.1029/2003JD004245.

Frauenfeld, O. W., T. Zhang, and J. L. McCreight (2007), Northern hemisphere freezing/thawing index variations over the twentieth century, Int Climatol, J., 27, 47-63.
Intergovernmental Panel on Climate Change (IPCC) (2007), Climate Change, 2007: The Physical Science Basis, Contribution of Working Group I to the Fourth Assessment Report of the Intergovernmental Panel on Climate Change, 996 pp., Cambridge Univ. Press, New York.

Khvorostyanov, D. V., P. Ciais, G. Krinner, S. A. Zimov, C. Corradi, and G. Guggenberger (2008a), Vulnerability of permafrost carbon to global warming. Part 2: Sensitivity of permafrost carbon stock to global warming, Tellus, Ser. B, 60, 250-264, doi:10.1111/j.16000889.2007.00336.x.

Khvorostyanov, D. V., G. Krinner, P. Ciais, M. Heimann, and S. A. Zimov (2008b), Vulnerability of permafrost carbon to global warming. Part 1. Model description and role of heat generated by organic matter decomposition, Tellus, Ser. B, 60, 265-275, doi:10.1111/ j.1600-0889.2007.00333.x.

National Research Council, (2003), Understanding Climate Change Feedbacks, 166 pp., Panel on Climate Change Feedbacks, Clim. Res. Comm., Washington D.C.

Poutou, E., G. Krinner, C. Genthon, and N. de Noblet-Ducoudré (2004), Impact of soil freezing on future climate change, Clim. Dyn., 23(6), 621639 .

Walter, B. P., S. A. Zimov, J. P. Chanton, D. Verbyla, and F. S. Chapin (2006), Methane bubbling from Siberian thaw lakes as a positive feedback to climate warming, Nature, 443, 71-75.

Zhang, J., and J. E. Walsh (2007), Relative impacts of vegetation coverage and leaf area index on climate change in a greener north, Geophys. Res. Lett., 34, L15703, doi:10.1029/2007GL030852.

Zhang, T., et al. (2005), Spatial and temporal variability in active layer thickness over the Russian Arctic drainage basin, J. Geophys. Res., 110, D16101, doi:10.1029/2004JD005642.

Zimov, S. A., E. A. G. Schuur, and F. S. Chapin III (2006), Permafrost and the Global Carbon Budget, Science, 312, 1612-1613.

P. Ciais and D. V. Khvorostyanov, Laboratoire des Sciences du Climat et de l'Environnement, LSCE/IPSL, CEA-CNRS-UVSQ, CE Saclay, l'Orme des Meristic, Batiment 701, F-91191 Gif-sur-Yvette Cedex, France. (dimitry.khvorostiyanov@1sce.ipsl.fr)

G. Krinner, Laboratoire de Glaciologie et Géophysique de l'Environnement, CNRS, Université Joseph Fourier-Grenoble, 54, Rue Molières, BP 96, F-38402 St. Martin d'Hères Cedex, France.

S. A. Zimov, North East Scientific Station, Pacifc Institute of Geography, Far East Branch of the Russian Academy of Sciences, P.O. Box 18, 678830 Cherskii, Russia. 